\title{
Effektlack mit neuen metallischen Akzenten
}

\author{
Metallische Akzente setzt ein neues, reflektierendes Effektlacksystem. Eine spezielle Formulierung \\ ermöglicht es, dass die wasser- beziehungsweise lösemittelbasierten Lacke als 1-, 2- und 3-schichtige
}

Aufbauten sowie in der RIM-Technologie direkt auf der Spritzgussmaschine verarbeitbar sind.

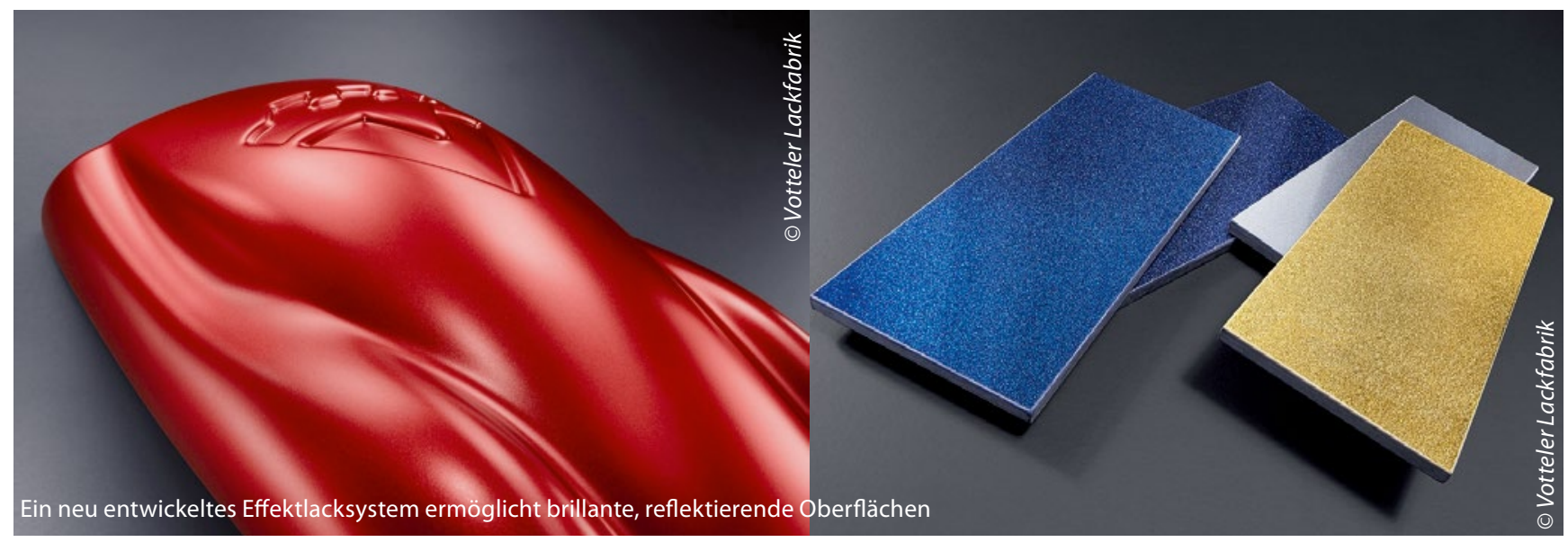

\begin{abstract}
A utomobilindustrie, Hausgeräte, Unterhaltungselektronik, Kosmetikindustrie und mobile Kommunikation - nur einige Branchen, in denen die Lackierung Produkte emotional in Szene setzt, ihnen eine individuelle Ausstrahlung verleiht und ihre Wertigkeit erhöht. Um eine hohe Oberflächenqualität in neuer Optik zu erzielen, wurde ein neues Effektlacksystem (VarioShine) von Votteler Lackfabrik entwickelt. Mit dem Effektlack lassen sich hochwertig spiegelnde Chrom-Optiken ebenso herstellen, wie brillant reflektierende und elegant changierende Oberflächen. Das Lacksystem eröffnet dadurch eine individuelle Gestaltungsfreiheit. Dazu trägt auch die Vielfalt der Farbtöne bei, in der die neuen Lacke mit lebendig metallisierenden Effekten zur Verfügung stehen. Die Glanzgrade reichen von hochglänzend bis matt, wobei die Oberflächen glatt, strukturiert oder mit Soft-Touch sein können. Die modernen Mattfarbtöne vermitteln einen Hauch von Raffinesse, Eleganz und Understatement sowie Wertigkeit.
\end{abstract}

Geht es um die Verarbeitung, überzeugen die Lacke ebenfalls durch hohe Flexibilität. Für Spritzverfahren stehen sie als wasserbasierte und Lösemittelsysteme für 1-, 2- und 3-schichtige Aufbauten auf fast allen gängigen Substraten zur Verfügung. VarioShine kann als lösemittelfreies System auch in der RIM-Technologie mit Selbstheilung (Reflow-Effekt) verarbeitet werden. Dieses Verfahren ermöglicht insbesondere bei höheren Stückzahlen eine deutliche Kostenreduzierung und Prozessverkürzung bei besseren Beständigkeiten, Produkteigenschaften und geringerem Ausschuss. Der Lack wird dabei parallel zum Spritzgussprozess auf der gleichen Anlage und im gleichen Zyklus aufgebracht, so dass das Teil bereits fertig beschichtet aus der Spritzgussanlage kommt.

\section{Optimales Colour-Matching}

Diese Vielseitigkeit gewährleistet einerseits, dass die Lackierung dauerhaft hohe Qualitätsanforderungen erfüllt. Dabei werden auch die Vorgaben der verschiedenen Branchen hinsichtlich Beständigkeit gegenüber mechanischer, chemischer und physikalischer Beanspruchung erfüllt. Andererseits können Anwender die neuen Effektlacke in dem für ihre individuellen Anforderungen optimal geeigneten und für sie kostengünstigsten Applikationsverfahren verarbeiten, wobei ein optimales Colour-Matching erzielt wird.

Die Applikation von VarioShineLacken kann in bestehenden Anlagen prozesssicher erfolgen. Votteler berät Anwender zum Einsatz sowie den Möglichkeiten des Effektlacksystems und definiert mit ihnen gemeinsam, welche Applikationsart für den jeweiligen Anwendungsfall optimal ist. I

\section{Kontakt:}

Votteler Lackfabrik GmbH \& Co. KG, Korntal-Münchingen, Tel. 071198045 ,

d.info@votteler.com,

www.votteler.com 